See discussions, stats, and author profiles for this publication at: https://www.researchgate.net/publication/345582733

\title{
Mitigating Isolation and Loneliness with Technology through Emotional Care by Social Robots in Remote Areas
}

Chapter · August 2020

DOI: 10.1049/PBHE024E_ch16

\section{CITATIONS}

9 authors, including:

Roger Andre Søraa

Norwegian University of Science and Technology

31 PUBLICATIONS 28 CITATIONS

SEE PROFILE

Jon Sørgaard

Norwegian University of Science and Technology

7 PUBLICATIONS 9 CITATIONS

SEE PROFILE

Some of the authors of this publication are also working on these related projects:

Project RoboCare View project

Project AAL eWare View project
READS

Eduard Fosch Villaronga

Leiden University

77 PUBLICATIONS 247 CITATIONS

SEE PROFILE

Pernille Nyvoll

University of Oslo

2 PUBLICATIONS 1 CITATION

SEE PROFILE 
Chapter 5.1

\title{
Mitigating Isolation and Loneliness with Technology through Emotional Care by Social Robots in Remote Areas
}

\author{
Roger A. Søraa (1,2,9), Eduard Fosch-Villaronga (4), João Quintas (5), Jorge \\ Dias (6), Gunhild Tøndel (3), Jon Sørgaard (1), Pernille Nyvoll (1), Henk \\ Herman Nap (7) \& J. Artur Serrano $(1,8)$
}

\begin{abstract}
This book chapter explores how experiences of isolation and loneliness in remote areas can be mitigated through social robots' emotional care. We first discuss the concept of being social and how that notion is changing with rapid digitalization. The research for this chapter zooms in the context of remote regions, characterized by vast geographical distances between cities, public services, and people's homes, in concrete, in northern and southern European regions. Then, the chapter discusses the Scandinavian term 'welfare technology,' and investigate different technological advances aiming towards bridging the gap loneliness poses. We propose the use and development of social robots equipped with emotional care support as a way of mitigating loneliness, given that the users do not experience the implementation of the technology into their daily life as paternalistic. We close the article with reflections on the consequences of such a sensible choice.
\end{abstract}

This paper is a postprint of a paper submitted to and accepted for publication in the IET book "Mobile Technologies for Delivering Healthcare in Remote, Rural or Developing Regions" and is subject to Institution of Engineering and Technology Copyright. The copy of record is available at the IET Digital Library.

Chapter DOI: 10.1049/PBHE024E ch16

Book DOI: 10.1049/PBHE024E

(1) Department of Neuromedicine and Movement Science, NTNU Norwegian University of Science and Technology, Trondheim, Norway

(2) Department of Interdisciplinary Studies of Culture, NTNU Norwegian University of Science and Technology, Trondheim, Norway

(3) Department of Sociology and Political Science, NTNU Norwegian University of Science and Technology, Trondheim, Norway

(4) eLaw Center for Law and Digital Technologies, Leiden University, Leiden, The Netherlands

(5) Laboratory for Automation and Systems, Instituto Pedro Nunes, Coimbra, Portugal

(6) Department of Electrical and Computer Engineering, Coimbra University, Coimbra, Portugal

(7) Vilans - National Expertise Centre on Long-Term Care, Team eHealth; Department of HumanTechnology Interaction, Eindhoven University of Technology, Eindhoven, The Netherlands

(8) Norwegian Centre for eHealth Research, University Hospital of North Norway, Troms $\varnothing$, Norway

(9) Corresponding author 


\subsubsection{Being 'social' with 'others'}

The idea of being social firmly interlinks with the idea of humans relating to other humans as social beings. The adjective 'social' is defined as 'relating to society or its organization' and the noun as being 'an informal social gathering, especially one organized by the members of a particular club or group' [1]. The renowned feminist techno-philosopher Donna Haraway suggests an extended multi-species approach. In her 2016 book Staying with the Trouble: Making Kin in the Chthulucene [2], she urges us to transcend this understanding of 'social' and form social relations with other species and entities in addition to the human interrelations. This understanding builds upon her earlier 'Cyborg Manifesto' [3], where the term 'cyborg' is used to discuss the merging of humans and technology.

In a Scandinavian context, being social strongly interlinks with its antonym, being lonely, which seems on the rise in modern societies. It is also a condition that strikes the population unevenly, as it is the oldest and youngest members of society who are experiencing loneliness the most. Loneliness is not dangerous, but persons can experience it as a personally disastrous situation. It can also be a barrier for social participation and therefore, a barrier for getting informal assistance from one's social network. These barriers may escalate loneliness into a societal problem: its prevalence places a strain on public service resources that could be eased if societal loneliness were mitigated. Consequently, there have been conversations in the public policy arena, especially concerning elderly care, about how to tackle loneliness. Addressing these problems offers a threefold benefit: advancing future welfare policy, supporting the growing welfare technology industry, and improving the quality of life of users.

In this book chapter, we explore how social robot's emotional care could mitigate experiences of isolation and loneliness in remote areas. We first map loneliness in different European regions, which are characterized by having vast geographical distances between cities, public services, and people's homes. We then introduce the concept of welfare technology and explain how technology is currently used to bridge the gap technology poses. As a possible solution, we propose the use and development of social robots equipped with emotional care. We review different European projects directed towards developing robots to assist older adults and persons with disabilities socially and explain their characteristics. We close the article with reflections on the consequences of such a sensible choice.

\subsubsection{Being lonely in remote areas}

\subsubsection{Being lonely in the North}

The Norwegian poet Inger Hagerup captured the essence of loneliness in her poetic work:

Tonight I'll close the door and only think about you.

I wonder if the loneliness still finds me [4].

In Scandinavian languages, 'loneliness' - and its more positive English-language cousin 'solitude' - share the same wording. Thus, self-chosen solitude does not have its term in the languages. Norway, covering $13^{\circ}$ latitude, from $58^{\circ}$ to $71^{\circ}$ North, (with the island archipelago Svalbard being $81^{\circ} \mathrm{N}$ ), is located in the northernmost part of 
continental Europe. It is projected that by 2040, it will be one of the key destinations of the Arctic Road and Belt silk road that will become available when the Northwest Passage becomes ice-free due to climate change. This will allow for faster trade, travel, and contact with Asian countries. Norway's total land area is $385170 \mathrm{~km}^{2}$, making it just a bit smaller than Japan - but with a population of only 5.3 million people. This small population density creates an intense and noticeable solitude and the settlements are quite dispersed when venturing outside of the largest cities. As the country is so stretched, this often leads to people living far away from their families, as well as people with no families and a lack of social network resources.

Loneliness is not a secluded feeling but is often interlinked with depression, loss of social status and networks and despair. Research has shown that loneliness is mainly present within the older population [5] and that it is particularly pertinent in people with few or no friends or family to provide emotional support [6]. Unlike other geographical settings of this book, which often focus on areas where it is common for families to live together in the same household for extended periods, northern societies are much more individual-based. It is not common for parents to live with their children after they become adults. Further, the democratic welfare state model allows for high female workforce participation for individuals that otherwise might have been operating in caregiving roles. A high degree of caring activities are outsourced from the family to public care facilities, e.g., nursing homes and home care services. However, despite being climatologically cold and geographically dispersed - and being perceived as socially cold - Norway ranked as the number one country in the Human Development Index for 2017 [7], had the second highest Gross National Product per capita in 2018 (ranking behind Switzerland and not counting microstates) [8] and ranked number three in the 2019 World Happiness Report (ranking behind Finland and Denmark) [9]. Norway is one of the happiest and most affluent countries in the world. Yet, even here loneliness can creep in.

\subsubsection{Being lonely in the South}

In order to contextualize loneliness in a broader geographical setting, we can look at other remote areas like the Portuguese Centro region. The Centro region is the second-largest national region and contains 22 percent of the total population in Portugal. In terms of demographic characterization, 25 percent of the Centro Region's population is older adults (65+), and the region has negative demographic growth. Most of the region is rural. This feature justifies the importance of designing interventions concerning aging, digital literacy, and access to health and social care (e.g., preventing loneliness, social exclusion, and isolation). The problem of aging and geographic isolation is especially prevalent in the innermost municipalities of the region, making them exceptionally high priorities for such interventions.

To overcome such challenges, the Centro Regional Coordination and Development Commission has incorporated a specific thematic objective into the Smart Specialization Strategy (RIS3) that addresses the topic of Information and Communications Technologies for improving health and quality of life. This thematic objective includes three specific sub-topics: Digital Future, Health Innovation and Active, and Healthy Ageing. Additionally, in line with the concerns raised by demographic changes and associated consequences, the Centro Region hosts a reference site of the European Innovation Partnership on Active and Healthy Ageing. The region has also developed an individual initiative - Aging@Coimbra [10]- a unique ecosystem that is developing best practices in healthcareassociated with active and healthy ageing. 


\subsubsection{Living well with 'welfare technology'}

Scandinavian research and policy often use the term 'welfare technology' to describe the 'new technologies in municipal- and specialist services [...] tested out and implemented at a large scale within a health and care context' $[11$, p. 4]. In an international context, this often falls under the terms 'Gerontechnologies' or 'Active Assisted Living (AAL) technologies,' or even medical technology or E-health technology. Welfare technologies are a large group of often digital devices with integrated platforms that public services use to promote welfare among patients and caregivers. Thus, they perform in a welfare state context, thereby giving them their distinct identity.

One of the chief goals of welfare technology is to allow people to better cope with their health impairments and improve their quality of life by increasing their autonomy [12]. The term has instrumental features, but it also points directly to an emotional aspect, i.e., the individual perception or experience of a kind of wellbeing. Lay associations to welfare technology are often related to elderly care. Governmental initiatives to develop the welfare technology industry were primarily grounded in arguments for the need for technology to solve challenges related to aging populations. However, the technology is now being used and developed to assist individual needs independent of age. Importantly, in the Scandinavian context, it is not one's functional or cognitive function level, medical diagnosis or age that defines the inclusion into the user group, but whether one is granted a health and care service through the public health and care service system.

Welfare technologies are further thought to contribute to support people's self-reliance, personal monitorization and enhanced knowledge about one's health status, while also encouraging social contact with caregivers, friends and loved ones [13]. They also have the potential to extend the work of doctors in medical interventions [14]. These goals are often complementary, but different technology traditions within the healthcare field have different terminology and emphasis. One example of this is the use of active lower-limb exoskeletons for rehabilitation and training of patients with reduced gait function [15]. Although exoskeletons are rehabilitative, medical technology, exoskeletons are also tools that increase patients' independence in their daily life by allowing them to participate more easily in social activities.

The policy also frames welfare technology as a tool for re-skilling healthcare work and for supplementing the increasing shortage of healthcare workers. The World Health Organization [16] has estimated that the global population over 60 will double by 2050 , implying a looming shortage of healthcare workers. Innovative approaches of care-through-technology are often thought of as a way to mitigate against the lack of workers, which results in a need for knowledge on how humans and machines may provide care together while simultaneously ensuring adequate working conditions. One example of this potential future trend is the recent use of 'virtual nurse visits' in Finland [17]. Virtual lunch groups offer the opportunity for older adults to have some company while preparing and eating their lunches with a nurse. The virtual care delivery is part of the strategic shift in Finland towards managing the consequences of aging, increased care demands, a decreasing birth rate, and lower tax revenues [18].

One area of growing importance within the field of welfare technology is the use of robotics and artificial intelligence. The Finnish Ministry of Social Affairs and Health proclaims that such novel technologies can provide a more refined well-being coaching and rehabilitation program and that they are crucial for prolonging living at 
home and ensuring effective and efficient care delivery services [19]. These advancements illustrate an essential challenge for welfare technology that must be solved at both an international and national policy level: they require policies that can ensure a balance between innovation and the protection of users' rights. As of 2019, the Future of Life Institute has identified national Artificial Intelligence (AI) strategies for more than half of the OECD countries, including Denmark, Finland, and Sweden, as having national AI strategies. However, Norway is not on that list, even though the need for such policies is evident [20]. At the European level, the latest robot and AI regulatory initiatives have scarcely dealt with healthcare, educational, or therapeutic robot technologies [21, 22]. Because of the potential benefits that $\mathrm{AI}$ and robotics have in the caregiving sector are increasingly being recognized, however, it seems to be a growing priority area for Europe [23].

\subsubsection{Social robots against loneliness}

Because the scientific community generally acknowledges the boundaries of what constitutes a robot as being difficult to pinpoint, the current state of the field is challenging to evaluate. The only consensus seems to lie on the role context plays in defining what robot technology is. Any robot that performs, with varying degrees of autonomy, useful services to humans are considered service robots. Manufacturing operations are relegated to traditional industrial robotics [24, 25]. Social robots are service robots and, as the name implies, they are primarily created to interact with humans socially. Social robots express and perceive emotions, communicate through highlevel dialogue, learn and recognize models of other agents, establish and maintain social relationships, and use natural cues such as gaze or gestures [26]. Robots that use these social abilities specifically to assist or support humans socially are called socially assistive robots [27].

Since the domestication of wildlife into pets, social interaction between humans and animals have played a significant role in society. Because humans tend to anthropomorphize [28], these social interactions can be replicated with robots, even though they are not biologically alive. These anthropomorphizations direct at zoomorphic robotic companions such as the dog AIBO, the seal robot PARO and the dinosaur PLEO; humanoid social robots such as Pepper and Asimo and more object-shaped robots such as pot-plant robot Tessa and the spherical Roomba vacuum cleaner.

Loneliness is one of the key areas where social robots can be particularly useful. We will here describe some detailed case studies of how robots have been used to solve or mitigate problems concerning loneliness, drawn from projects we have conducted with a specific focus on welfare technologies.

\subsubsection{Examples of European and National projects on welfare technology}

In recent years there has been significant investment on research and innovation on social robots and welfare technologies both on a European and a national level. Below, we show some examples of projects that we have been involved with, and how they have focused on this topology:

SocialRobot (2011-2015) was a FP7 (EU's $7^{\text {th }}$ Framework Programme for Research and Technological Development) project aimed to provide assistive services and companionship robots for elderly people — the project primarily geared towards assisting in navigation indoors and unstructured environments and providing 
affective and empathetic interactions. In its work, it ensured that it took into account the capabilities of and acceptance by elderly users. The project made an outstanding contribution in terms of identifying individual needs and requirements related to aging (e.g., physical mobility limitations or/and cognitive decline) that social robotic interventions should take into account. It also emphasized the provision of support through timely involvement of care teams - including family members, neighbors, and friends - that would collaborate dynamically and virtually at different times and without regards to their physical location. It included behavior analysis to adapt to changing social relationships and contexts of older adults as they age.

VictoryaHome (2013-2015) For those in the later years of their life, living alone can be challenging and unsafe. It often places a heavy burden on friends and family who routinely offer informal care. As the population ages, this burden will increase, placing an unsustainable demand on public care systems. VictoryaHome was a project cofunded by the AAL - European Active and Assisted Living Joint Programme, which addressed the needs of the elderly living alone at home. It included partners in Norway, the Netherlands, Sweden, and Portugal.

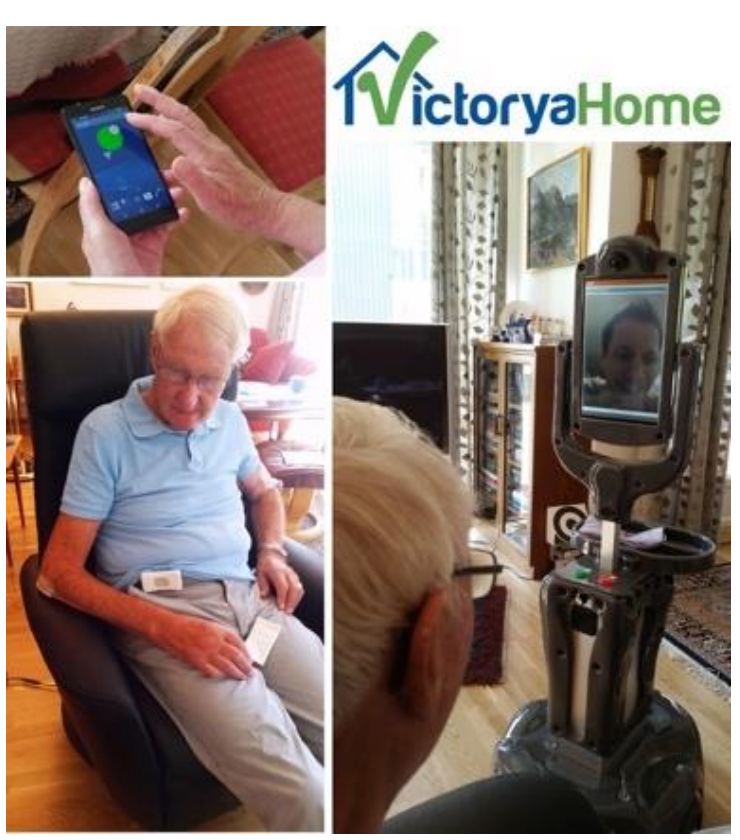

VictoryaHome offers an open platform able to integrate the following services: activity monitoring, fall detection, medication adherence, and telepresence visits. The main scenario of using VictoryaHome builds on the following scenario:

Imagine old Irene with a robot that knew her schedule, circumstances, and could share this knowledge with her caregivers in case there is a problem. The caregiver could teleoperate the robot and see what happened and take action. Having the possibility to check on the patient via the robot would improve the reaction time of caregivers while reducing the costs of rushed or unnecessary interventions. [29]

Figure 16.1 VictoryaHome.

The robot used in the VictoryaHome system was the Giraff, a telepresence robot that allows one person to enter or visit another person in a remote place virtually. The robot may be remotely controlled using a personal computer, via the Internet, using an accessible user graphical interface. The user - normally a caregiver - can move freely about the remote place simply by moving the computer mouse and interact with the residents there via videoconferencing. Access is secured via login and password, and the communication is fully encrypted. On 24 September 2015 VictoryaHome received the award for the best project in the EU AAL program. 
GrowMeUp (2015-2018), a Horizon 2020 project, built on the SocialRobot projects's results and extended them with novel concepts and features including context-awareness - which allows it to learn the older persons needs and habits over time and adapt its functionality, compensating for as the older person' capabilities degrade over time over time - and cloud robotics, which enables the sharing and distribution of knowledge with multiple robots performing a similar job.

eWare (2017-2020) The European AAL eWare project provides people with dementia and their (in)formal caregivers a novel and user-friendly solution that can support independent living by combining social robotics and lifestyle monitoring. Lifestyle monitoring is a technology that was developed specifically to support caring for people with dementia. This technology involves monitoring for the person with dementia to perform specific desired activities, such as going to bed, getting a meal, or watering the plants. These activities can be defined, including the timeframes the patient should perform the actions, by the (in)formal caregiver via an eWare mobile application. The technology then monitors for signs that an activity is taking place, e.g. activity in the kitchen when it is time to eat. The eWare program integrated a social robot - Tessa- to allow for bidirectional communication. The robot looks like a jar with a plant in it and has blinking eyes.

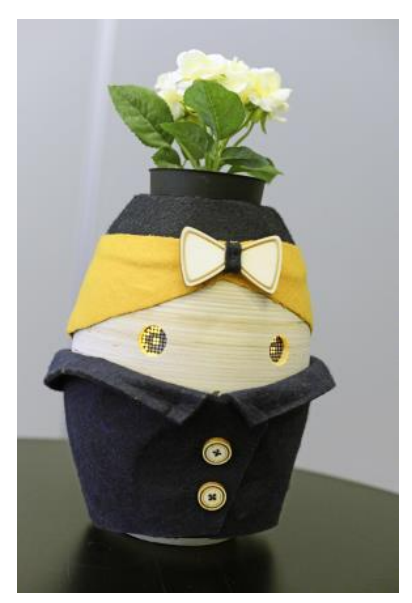

The caregiver can program specific verbal reminders that the Tessa will speak in specific time frames to remind person with dementia to do these everyday lifestyle tasks that they may have forgotten to do. If needed, these reminders can be given a second or third time with increasing, but always friendly, urgency. If the person performs the tasks within the designated timeframes, no verbal reminders are given. Caregivers can thus both gain an insight in the daily life pattern of a person with dementia and reduce the burden of care. Communication between both can be enhanced. In addition to improving care for the patient, such technology can reduce caregiver's distress [29] and thereby extend the period that the informal caregiver can sustain the care needs for people with dementia [30].

Figure 16.2 The Tessa robot from Tinybots used in the eWare project

EuroAge (2017-2020), an Iberian POCTEP (Programa de Cooperación Interreg VA España-Portugal) project focused on the development of innovative initiatives for the promotion of active aging in the EuroACE region (Alentejo and Centro (Portugal) and Extremadura (Spain)). Its objective was to promote active aging in the areas of physical, cognitive and socio-emotional activity, with the primary objective of improving the quality of life and increasing healthy life expectancy through the integration of Portugal-Spain cross-border technical-scientific knowledge. One of the lines of work of this project was in the area of robotics, highlighting the great potential that exists in the EuroACE region, concerning Social and Assistive Robotics for the elderly or otherwise dependent individuals. In this project, the previous results from SocialRobot and GrowMeUp were extended with further integration with the home Internet of Things (IoT) infrastructure (e.g., camera network) and a virtual agent (e.g., human-like avatar) that can 'coexist as an integrated solution.

My robot friend (2017-2019) is a project concerned with how older adults are often not included in the design processes and feedback loops of social robots and how this user participation can be improved — the project aimed 
to include older adults through elderly municipality councils as advisors and knowledge brokers. Here, we wanted to meet the elderly with an open mind and hear their impressions. We used different social robots, like the robot Pepper - developed by Softbank - and eWare's Tessa, as venture points for discussions and gained significant insight from the elderly on how robots could be used for being more social. One key insight was that it is not the robots in themselves that become the important change agents in people's lives, but rather the intricate socionetworks of care that they make possible and strengthen.

LIFEBOTS Exchange (2019-2023) Lifebots is a project which seeks to increase cross-sectoral, international and interdisciplinary collaboration in the area of social robotics technology, particularly within the care and health sector. This is facilitated by the exchange of personnel between multiple European countries and South Korea. While on the exchange, the personnel works on advancing the current maturity of social robotics and investigate how human users and social robotics can cohabitate. Having user organizations, Small and medium-sized enterprises (SMEs), and academic institutions as partners allows for a multifocal approach. The project is financed by the Research and Innovation Staff Exchange (RISE) programme, which is part of the Marie Skłodowska-Curie Actions (MSCA) under the European Union's research and innovation framework programme Horizon 2020. The project ties together knowledge from a lot of different projects on social robots, in order to learn from past interdisciplinary, international and intersectoral collaborations.

\subsubsection{Critical features of social robots}

Based on the projects and robots described above, we here list certain essential elements to social robots that can be critical items to reflect upon when designing and implementing social robots that mitigate loneliness:

\begin{tabular}{|l|l|}
\hline Social & $\begin{array}{l}\text { The ability to provide emotional support, emotional care and even love is an essential feature of } \\
\text { social robots. In addition to the actions of the robot, this can include the possibility of enabling } \\
\text { external communication and interaction with the outer world. }\end{array}$ \\
\hline $\begin{array}{l}\text { Natural } \\
\text { features }\end{array}$ & $\begin{array}{l}\text { The capability of allowing interaction by means that feel 'natural' to the user (e.g. gestures, } \\
\text { speech, etc.) and adaptation to the user's general profile, specific needs and intentions were } \\
\text { identified as high priority requirements. In the AAL domain, these features must address the } \\
\text { needs of users with cognitive or physical skills degradation (e.g. elderly or impaired people) and } \\
\text { should aim to compensate for these limitations, hence enriching user experience and } \\
\text { accessibility. }\end{array}$ \\
\hline Robustness & $\begin{array}{l}\text { Robots should not break down in the course of operation. Robots also need to be robust so they } \\
\text { do not break while interacting with humans. For instance, when robots tend to look more } \\
\text { humanoid, there are often tendencies for spectators to want to shake the robots' hand, which } \\
\text { often are not created for multiple humans squeezing their hands repeatedly. Depending on the } \\
\text { context where the robot is, roboticists will have to take into account environmental aspects; for } \\
\text { example, most robots are not that well fitted to deal with natural environments such as forests, } \\
\text { mud or rain. }\end{array}$ \\
\hline
\end{tabular}




\begin{tabular}{|c|c|}
\hline $\begin{array}{l}\text { Technical } \\
\text { reliability }\end{array}$ & $\begin{array}{l}\text { How humans use technology can depend on whether humans trust the robot to do what it is } \\
\text { supposed to at the right time. When technical bugs and hardware or software malfunction makes } \\
\text { robots behave in unexpected, or even dangerous ways, human acceptance rate can drop } \\
\text { drastically. As Salem et al. [30] highlight, the reliability also refers to the level of trust that the } \\
\text { designer's intentions are aligned to the needs of the user. }\end{array}$ \\
\hline $\begin{array}{l}\text { Privacy \& } \\
\text { Security } \\
\text { concerns }\end{array}$ & $\begin{array}{l}\text { Who is listening on the other side of the robot's sensors is essential to protecting the privacy } \\
\text { rights of the users. Robots inserted into the homes of users represent an interface with the most } \\
\text { intimate place a person has. Behavioral and health data are highly sensitive and have special } \\
\text { consideration under the European data protection legal framework and deserve the utmost } \\
\text { protection. }\end{array}$ \\
\hline $\begin{array}{l}\text { Inter- } \\
\text { operability }\end{array}$ & $\begin{array}{l}\text { Social robots' ability to learn from different technological systems (e.g. integration with IoT } \\
\text { devices for home) is critical to creating better user experiences. If one robot learns something } \\
\text { crucial about human behavior, it is beneficial if other robots of the same type can inherit the } \\
\text { knowledge and implement it in future interactions while still adhering to individual } \\
\text { considerations of human users. The use of cloud robotics and standard interoperable systems may } \\
\text { speed learning processes and also ease mass implementation. }\end{array}$ \\
\hline Usability & $\begin{array}{l}\text { If robots are not easy to use, their usage does not last long. Intuitive plug-and-play technology } \\
\text { could replace challenging, long tutorials. For different users, different thresholds of using robots } \\
\text { exist, and by making the user process as intuitive and straightforward as possible robots can } \\
\text { integrate into the lives of everyday users more easily. }\end{array}$ \\
\hline $\begin{array}{l}\text { People- } \\
\text { centered } \\
\text { design }\end{array}$ & $\begin{array}{l}\text { Taking into account users' needs and interests from the first stage of development increases the } \\
\text { effectiveness of the future robot implementation process as well as the quality and usability of } \\
\text { the final product. It also improves the accessibility of interactive systems by integrating } \\
\text { theoretical models with practical user performance feedback. As the World Health Organization } \\
\text { notes, 'integrated people-centred health services means putting the comprehensive needs of } \\
\text { people and communities, not only diseases, at the centre of health systems, and empowering } \\
\text { people to have a more active role in their own health.' [31] }\end{array}$ \\
\hline High Cost & $\begin{array}{l}\text { The pursuit of the most appropriate technological platform with the most advanced features } \\
\text { usually leads to a price tag that is not compatible with the existing budgets both from individual } \\
\text { buyers (the user at home and/or their families) and the national healthcare services. Thus, making } \\
\text { cost reasonable is essential for the largescale adoption of technology. }\end{array}$ \\
\hline
\end{tabular}




\subsubsection{Reflections on robots, the elderly and loneliness}

Implementing technology into the lives of users is not a linear process. How social robots can become part of the daily lives of older adults in their own homes is a significant challenge for welfare technology/AAL. In order to become a social resource for the elderly and act as an intermediary between people living at home, their relatives and the municipal health and care services, social robots need either a certain level of intelligence or perception of intelligence. The potential of robots as assistive technology to supplement human contact in care may primarily address the goal of increasing individual autonomy, thus bridging the loneliness that public service users may experience due to functional reductions. However, whether such technology is also used to replace human contact is currently being critically discussed within social science research on technology in care [32, 33]. Europe is aware of this challenge and has reiterated that human contact is an essential aspect of social care, and that robot technologies should not replace $[22,24]$. Norwegian health and care authorities emphasize the same standpoint [34]. Transitions of welfare technology from having a supplementing role to replacing care personnel can be anticipated to take place at street-level in the services, where discrete conflicts about the distribution of resources within and between services take place.

Robot technology could be an interface that connects older adults in remote places to social networks, putting them in contact with relatives, friends, and doctors. However, the continuous use of companion robots could also intensify and exacerbate the loneliness these people feel. Although they would be 'in contact' with other people, they may also experience this as a deprivation of the warmth of human-human encounters. In this sense, some European institutions try to understand to what extent the respect for family life should also include a possible 'right to meaningful human contact' [35], although we wait for more guidance on the realization of such a right in specific situations.

Turkle [36] captures the long-term consequences of such technologies and warns that technologies, even if meant to combat loneliness, might make us be 'alone together' staring blankly into our screen-worlds, forgetting the 'real world' and being lonelier than we were before we had the technology. As robots are emissaries of the digital, good design is crucial to keep humans rooted in the offline world as well, in particular when it comes to healthcare, where illness exists not as digital representations but in real patients even if, on the other hand, virtual escape might lead to the forgetting of physical pains. Responsible technological development with a deep and interdisciplinary understanding of human affection is strongly needed.

The introduction of social robots in societies is a complex matter and requires including many different perspectives, including the gendered aspect of aging and technology. Women, in general, live longer than men. This demographic trend increases the older the sample population is. Designing robots with gender in mind is essential [37], as there might be physical or cultural differences between users based on gender [38]. Gender can be used both as an inclusive and an exclusion parameter, and it is, in our experience, essential to include a representative part of the population in planning, making, using and analyzing technology. 


\subsubsection{Concluding remarks}

This book chapter has explored how social robotic emotional care could mitigate isolation and loneliness. We first discussed the concept of being 'social' and how that notion is changing with rapid digitalization. We paid particular attention to remote regions and explored the Scandinavian term 'welfare technology,' while also situating how loneliness can be a geo-cultural feeling both in the northern regions and southern locations — such as the Portuguese case. As a solution to these issues, we illustrated our case with different collaborative projects on human-robot interaction.

As Scandinavia is a wealthy region, but deficient in population numbers, situational understanding of robotic development and implementation in the region could provide highly fruitful for other regions doing similar tests. With increased globalization, new trade ways, technology brokering, and advancement, it becomes essential to ensure that society includes ways to connect individuals in remote places to the outer if they want. Having the choice of connecting to other individuals not only could reduce the negative aspects of loneliness, but also improve their self-esteem and positivity. Social robots could be one component in achieving this goal as part of a seamless web of care practices.

\section{Acknowledgements}

This chapter has been partially funded by the LIFEBOTS Exchange project funded by the European Union's Horizon 2020 research and innovation programme under the Grant Agreement No. 824047; and by the LEaDing Fellows Marie Curie COFUND fellowship, a project that received funding from the European Union's Horizon 2020 research and innovation programme under the Marie Skłodowska-Curie Grant Agreement No. 707404.

\section{References}

1 Lexico. Definition of 'social' [online]. N.d. Available from https://www.lexico.com/en/definition/social [Accessed 14 September 2019]

2 Haraway D. Staying with the Trouble: Making Kin in the Chthulucene. Durham: Duke University Press; 2016

3 Haraway D. 'A manifesto for cyborgs: Science, technology, and socialist feminism in the 1980s' in Seidman S (ed.). The Postmodern Turn: New Perspectives on Social Theory. Cambridge: Cambridge University Press ;1994 pp. 82-115

4 Hagerup, I. Mitt Kkip Seiler. Oslo: Aschehoug; 1951 (translated by authors)

5 Cohen G. D. 'Loneliness in later life'. American Journal of Geriatric Psychiatry. 2000; 8: 273- 75

6 Sorkin D., Rook K. S., \& Lu J. L. (2002). 'Loneliness, lack of emotional support, lack of companionship, and the likelihood of having a heart condition in an elderly sample'. Annals of Behavioral Medicine. 2002; 24: 290-98

7 United Nations Development Programme. Human Development Reports: Norway [online] n.d. Available at http://hdr.undp.org/en/countries/profiles/NOR [Accessed 14 September 2019] 
Chapter 5.1 Mitigating isolation and loneliness with technology through emotional care by social robots for remote areas.

8 The World Bank. GDP Per Capita (Current US\$) [online] n.d. Available at https://data.worldbank.org/indicator/NY.GDP.PCAP.CD [Accessed 14 September 2019]

9 Helliwell J. F., Layard R., \& Sachs J. D. World Happiness Report 2019. Available at https://s3.amazonaws.com/happiness-report/2019/WHR19.pdf [Accessed 14 September 2019]

10 Ageing@Coimbra [online] Available at https://ageingcoimbra.pt [Accessed 14 September 2019]

11 Moser I. (ed.) (2019) Velferdsteknologi - en ressursbok. Oslo: Cappelen Damm AS.

12 Nakrem S. \& Sigurjónsson, J.B. Velferdsteknologi i praksis. Oslo: Cappelen Damm AS; 2017

13 Broadbent, E. MacDonald, B. Robinson, H. (2015) 'Group sessions with Paro in a nursing home: Structure, observations and interviews'. Australasian Journal on Ageing. 2016; 35(2): 106-12

14 Butter M, Rensma A, Van Boxsel J, Kalisingh S, Schoone M, Leis M, Gelderblom G, Cremers G, de Wilt M, Kortekaas W, Thielmann A. Robotics for Healthcare: Final Report. Brussels: DG Information Society, European Commission; 2008

15 Gorgey AS. 'Robotic exoskeletons: The current pros and cons'. World Journal of Orthopedics. 2018; 9(9): 112-19

16 World Health Organization. Ageing and Health [online]. 5 February 2018. Available from https://www.who.int/news-room/fact-sheets/detail/ageing-and-health [Accessed 14 September 2019]

17 Johnson S. 'Virtual visits: how Finland is coping with an ageing population'. The Guardian [online]. 26 June 2019 Available at: https://www.theguardian.com/society/2019/jun/26/virtual-visits-finland-remotecare-ageing-population?CMP=share btn tw [Accessed 14 September 2019]

18 Kauranen A, Rosendahl J. Record-low birth rate threatens Finland's welfare system: Finance Minister [online]. 28 November 2018. Available at https://uk.reuters.com/article/us-finland-population/record$\underline{\text { low-birth-rate-threatens-finlands-welfare-system-finance-minister-idUKKCN1NY1RP }}$ [Accessed 14 September 2019]

19 Finnish Ministry of Social Affairs and Health. Well-Being and Health. AiRo programme; 2018. Available at https://stm.fi/en/artikkeli/-/asset_publisher/tekoaly-ja-robotiikka-parantavat-ihmisten-hyvinvointiahyteairo-ohjelma-vauhdittaa-toteutuksia [Accessed 14 September 2019]

20 Future of Life Institute. Global AI policy: How countries and organizations around the world are approaching the benefits and risks of AI [online]. n.d. Available at https://futureoflife.org/ai-policy/ [Accessed 14 September 2019]

21 European Parliament. Civil Law Rules on Robotics European Parliament resolution of 16 February 2017 with recommendations to the Commission on Civil Law Rules on Robotics (2015/2103(INL)). Available at http://www.europarl.europa.eu/doceo/document/TA-8-2017-0051_EN.html?redirect [Accessed 14 September 2019]

22 Fosch-Villaronga E. Artificial Intelligence, Healthcare, and the Law: Regulating Automation in Personal Care. Routledge; 2019

23 European Parliament. Report on a comprehensive European industrial policy on artificial intelligence and robotics (2018/2088(INI)). Available at http://www.europarl.europa.eu/doceo/document/A-8-20190019 EN.pdf [Accessed 14 September 2019]

24 Quintas JM (2018). Context-based Human-Machine Interaction Framework for Artificial Social Companions. Doctoral dissertation, 00500: Universidade de Coimbra; 2018 
25 International Federation of Robotics (2019). Service Robots. Retrieved from https://ifr.org/service-robots [Accessed 15 September 2019].

26 Fong T, Nourbakhsh I, \& Dautenhahn K. 'A survey of socially interactive robots'. Robotics and Autonomous Systems. 2003;42(3-4):143-66

27 Feil-Seifer D \& Mataric MJ. 'Defining socially assistive robotics'. IEEE 9th International Conference on Rehabilitation Robotics, Chicago, IL, 2005. ICORR; 2005, 465-68.

28 Duffy B R. 'Anthropomorphism and the social robot'. Robotics and Autonomous Systems. 2003; 42(34):177-90

29 AAL Programme. VictoryaHome [online] n.d. Available at http://www.aaleurope.eu/projects/victoryahome/ [Accessed on 14 September 2019]

30 Salem M, Lakatos G, Amirabdollahian F, \& Dautenhahn K. 'Towards safe and trustworthy social robots: ethical challenges and practical issues'. In International Conference on Social Robotics, 26 October 2015. Springer, pp. 584-593.

31 World Health Organization. WHO Framework on Integrated People-Centered Health Services [online] n.d. Available at https://www.who.int/servicedeliverysafety/areas/people-centred-care/en/ [accessed on 14 September 2019]

32 Pols J \& Moser I. (2009). 'Cold technologies versus warm care? On affective and social relations with and through care technologies'. ALTER, European Journal of Disability. 2009; 3(2): 159-78

33 Tøndel G. (2018). 'Omsorgens materialitet: trygghet, teknologi og alderdom [The Materiality of Care: Safety, Technology and Old Age]'. Tidsskrift for omsorgsforskning [Journal of Care Research]. 2018; 4(3): $287-297$

34 Norwegian Ministry of Health and Care Services (2011). Innovation in the Care Services. White paper, 2011: 11 .

35 Parliamentary Assembly of the Council of Europe (PACE). Human Rights in the Robot Age: Challenges Arising from the Use of Robotics, Artificial Intelligence, and Virtual and Augmented Reality. The Hague: Rathenau Instituut; 2017. Available at https://www.rathenau.nl/sites/default/files/201802/Human\%20Rights\%20in\%20the\%20Robot\%20Age-Rathenau\%20Instituut-2017.pdf [Accessed 14 September 2019]

36 Turkle S. Alone Together: Why We Expect More from Technology and Less from Each Other. Hachette UK; 2011

37 Søraa RA. 'Mechanical genders: how do humans gender robots?'. Gender, Technology and Development. 2017;21(1-2): 99-115.

38 Gendered Innovation. Exploring Markets for Assistive Technologies for the Elderly [online] n.d. Abailable at http://genderedinnovations.stanford.edu/case-studies/robots.html\#tabs-2 [Accessed 14 September 2019] 


\section{Photo credits}

Figure 16.1 Picture from the VictoryaHome Consortium in 2005.

Figure 16.2 Picture provided by Kim Sørenssen/NTNU 